\title{
ASPECTOS METODOLÓGICOS DA RESOLUÇÃO DE PROBLEMAS NA FORMAÇÃO DE PROFESSORES DE CIÊNCIAS DA NATUREZA
}

\author{
Mara Elisângela Jappe Goi* \\ Flávia Maria Teixeira dos Santos**
}

\begin{abstract}
Resumo: Neste trabalho, relata-se uma experiência na formação de professores de ciências da natureza que teve por objetivo aprofundar os aspectos conceituais e metodológicos da Resolução de Problemas. Para isso, procurou-se dialogar com diferentes referenciais teóricos do campo epistemológico, pedagógico e psicológico da educação. Discute-se aspectos apreendidos durante as etapas do curso de formação. Foram analisados os registros do diário de campo das pesquisadoras e os depoimentos dos professores no decorrer do curso de formação. A experiência realizada e os dados obtidos indicaram que o desenvolvimento de competências no processo de elaboração de problemas pode ser realizado em curso de formação, como também permitiu levantar uma série de questões da formação de professores. Assim, entendese que esse processo é uma tarefa complexa, principalmente quanto à formação práticoreflexiva e à ampliação de habilidades e estratégias didáticas no que se refere à produção e utilização de material pedagógico.
\end{abstract}

Palavras-Chave: Formação de professores. Ensino de Ciências. Metodologia de Resolução de Problemas.

\section{Introdução}

Neste trabalho, discutem-se os resultados de um curso de formação continuada, realizado em uma universidade pública do estado do Rio Grande do Sul. O curso aprofundou a Metodologia de Resolução de Problemas (RP), com professores da Educação Básica de Ciências da Natureza, na análise e produção de situações-problema e na utilização dos problemas produzidos nas salas de aula da Educação Básica.

$\mathrm{Na}$ formação, foram trabalhados os aspectos epistemológicos, pedagógicos e psicológicos da RP na formação de professores. Esse aprofundamento contou com os estudos sistemáticos de Larry Laudan, John Dewey e Jerome Bruner.

A partir de experiências vivenciadas pelos professores formadores (GOI, 2004, 2014; GOI; SANTOS, 2003, 2009, 2015, 2017; SANTOS; GOI, 2005, 2012), foi possível elaborar

\footnotetext{
* Professora da Universidade Federal do Pampa (UNIPAMPA), Brasil. Doutorado em Educação pela Universidade Federal do Rio Grande do Sul (UFRGS), Brasil. E-mail: maragoi28@gmail.com

${ }^{*}$ Professora da Universidade Federal do Rio Grande do Sul (UFRGS), Brasil. Doutorado em Educação pela Universidade Federal de Minas Gerais (UFMG), Brasil. E-mail: flavia.santos@ufrgs.br
} 
um curso de aprofundamento teórico metodológico, considerando que os professores da Educação Básica não apresentam os conhecimentos necessários para a utilização da metodologia de Resolução de Problemas em seus contextos escolares.

Nas experiências de formação em que o grupo de pesquisa da UNIPAMPA e UFRGS realizam em eventos da área do Ensino de Química, é possível apresentar aos professores a metodologia de RP e verificar como ela pode ser implementada nas salas de aula. Nesses cursos, é plausível estabelecer aspectos do marco teórico da metodologia, apresentar exemplares produzidos por outros grupos de professores e incentivar a produção de problemas pelos cursistas.

Os Cursos de extensão universitária, implementados pelo mesmo grupo de pesquisa entre 2010 e 2018, objetivam um maior aprofundamento teórico sobre os aspectos epistemológicos, pedagógicos e psicológicos da RP. Permitem a elaboração mais cuidadosa dos problemas, que passam por diversas revisões dos pares e da equipe de professores. Além disso, os cursistas, docentes da Educação Básica, são incentivados a aplicar os problemas nas suas salas de aula e discutir os resultados dessa implementação com seus colegas em grupo de formação.

O debate sobre RP também é realizado nos cursos de formação inicial de professores, entre eles destacam-se o curso de Licenciatura em Química da UFRGS e o curso de Licenciatura em Ciências Exatas da UNIPAMPA. Nesses espaços formativos, o desenvolvimento das bases teóricas e o acompanhamento do professor contribuem para a construção de problemas mais elaborados, alguns dos quais foram utilizados em experiências didáticas durante os estágios supervisionados dos licenciandos e foram publicados na forma de Trabalhos de Conclusão de Curso de Licenciatura (BENTLIN, 2009; BOLZAN, 2015; BOLZAN, 2015a; FREITAS, 2015; LEITE, 2009; PERES, 2015; SANTOS, 2009; SILVA, 2017).

Essas discussões também são realizadas em curso de Especialização e Mestrado profissional em Ensino de Ciências da UNIPAMPA, nos quais os professores em formação têm disciplinas que tratam dos aspectos conceituais e metodológicos da RP. Esses professores produzem uma sequência de problemas para que possam ser apresentados e validados entre os pares no decorrer do componente curricular.

Observa-se que, em todos os casos, quando são fornecidos ao professor argumentos teóricos e metodológicos para o trabalho com RP, eles se sentem mais seguros para utilizar esta estratégia metodológica em suas salas de aula. Assim, nessa perspectiva, apresenta-se e discutese os dados extraídos de um curso de formação continuada. A experiência realizada e os dados 
obtidos indicam que o desenvolvimento de competências no processo de elaboração e resolução de problemas pode ser realizado em curso de imersão com professores da área de Ciências da Natureza. A experiência relatada vincula-se à constituição de um grupo de formação continuada de professores e justifica-se pela necessidade de instituir um grupo docente embasado no estudo da RP no Ensino de Ciências.

\section{Caminhos metodológicos}

Este trabalho é de cunho qualitativo que, para Lüdke e André (1986, p.11-13), acontece no "[...] ambiente natural como fonte direta de dados e tendo o pesquisador como seu principal instrumento[...]". Os dados coletados são descritivos e há uma preocupação maior com o processo do que com o produto final. Os conjuntos de dados coletados foram levantados em espaços de discussão: na universidade e nas escolas da Educação Básica. Neste texto, apresentase e discute-se dados que foram identificados no percurso do curso de formação.

Na busca por um percurso metodológico coerente com os objetivos deste trabalho e com as exigências da complexidade do contexto educacional (que requer a utilização de uma pesquisa capaz de contemplar as novas demandas educativas), destaca-se, como método, o Estudo de Caso. Stake (2005) aponta que dos casos particulares pode-se aprender muitas coisas gerais que sustentam a formação de um novo grupo, surgindo, assim, a oportunidade de modificar as generalizações mais antigas. O estudo de caso pode levar os investigadores a propor conclusões a partir das observações e analisar outros dados que foram investigados.

Para tanto, foram elaborados Diários de Campo (PORLÁN; MARTíN, 1998), nos quais as pesquisadoras realizaram o registro das observações mais significativas do processo formativo.

Também se analisam os problemas produzidos pelos professores em formação. Esses problemas podem ser classificados conforme a área a que pertencem, o conteúdo desenvolvido em cada situação-problema, as dicotomias ${ }^{1}$ apresentadas na literatura do tipo problemas

\footnotetext{
${ }^{1}$ Classificação dicotômicas para uma situação-problema (WATTS, 1991): Aberto-fechado: um problema aberto permite ao resolvedor chegar a várias soluções. Um problema fechado só permite uma solução.

Formal-informal: um problema formal foi previamente pensado e normalmente é apresentado com uma formulação desejada. Um problema informal não tem uma formulação escrita, é pouco claro e surge de contextos de discussões.

Curricular-não-curricular: os problemas curriculares são aqueles oriundos dos conteúdos da escola ou de tarefas escolares. Os não curriculares são aqueles que não necessitam de conteúdos estabelecidos pela escola para serem solucionados.

Livre-orientado: um problema livre é aquele que durante a resolução não é oferecido nenhum tipo de ajuda. Um problema orientado é aquele que tem assessoria, diálogo, reflexões durante a sua resolução.

Dado-apropriado: um problema dado é aquele do qual o estudante não participa da escolha e da sua formulação O problema apropriado é aquele que o estudante participa da sua gênese. Um problema dado pode se transformar
} 
dedutivos ou indutivos, problemas definidos ou indefinidos, problemas escolares, científicos ou problemas do cotidiano, problemas abertos ou fechados, problemas formais ou informais, problemas curriculares ou não curriculares, problemas livres ou orientados, problemas dados ou apropriados, problemas reais ou artificiais (WATTS, 1991). Como também pode ser classificado de acordo com a natureza de cada situação-problema, natureza teórica, experimental ou teórica versus experimental. Os problemas teóricos não necessitam de uma atividade experimental para solucioná-los, enquanto os teóricos versus experimental ou puramente experimental necessitam de experimentos para chegar a uma resolução adequada (LOPES, 1994)

\section{Contexto da pesquisa}

A pesquisa foi realizada no grupo de formação continuada de professores que foi desenvolvido na UFRGS. O grupo é coordenado por docentes da UFRGS e da UNIPAMPA. Esse curso teve apoio do Fundo Nacional de Educação (FNDE) e do Centro de Formação Continuada de Professores (FORPROF/UFRGS) e integra-se ao Plano Básico de Formação dos Profissionais da Educação Básica do Ministério da Educação.

Esse trabalho com professores atendeu uma das principais demandas identificadas no Estado do Rio Grande do Sul, a formação continuada. Como indicam as investigações realizadas pelo grupo de pesquisa da UFRGS e UNIPAMPA (BORGES, 2018; LEITE, 2013; MENEZES et al., 2017), além dos problemas identificados na formação inicial dos professores, o Fórum Estadual Permanente de Apoio à Formação Docente do Rio Grande do Sul identificou a falta de formação continuada dos professores, o que vem prejudicando o desenvolvimento profissional docente no Estado (LEITE, 2013).

Os professores em formação implementaram suas propostas nas diferentes escolas da Educação Básica da grande Porto Alegre. Essas escolas são, na maioria, da rede pública de ensino, sendo que apenas dois (2) dos vinte e quatro (24) professores são docentes da rede privada de ensino de Porto Alegre. Os sujeitos lecionam no Ensino Fundamental II e no Ensino Médio e são formados em Ciências da Natureza (Física, Química ou Biologia). Alguns desses

em um apropriado, desde que haja discussão, negociação de forma que este problema vá de encontro às necessidades internas dos estudantes.

Reais-artificiais: os problemas reais são aqueles relacionados com as necessidades da sociedade. Os problemas artificiais, não estão relacionados diretamente às necessidades da sociedade, mas para responder a interesses acadêmicos, escolares, científicos ou à curiosidade especulativa. 
sujeitos têm formação em outras áreas do conhecimento, a saber: Bacharel em Química (1), Engenharia Química (1), Bacharel em Biologia (1) e Química Industrial (1).

\section{A ação de extensão universitária}

A formação foi realizada em três módulos, totalizando 90 horas de extensão. No módulo 1, foram aprofundados os referenciais teóricos epistemológicos, pedagógicos e psicológicos da RP. No módulo 2, os professores produziram, validaram e implementaram seus problemas nos contextos escolares e, no módulo 3, os professores realizaram uma discussão dos resultados após a aplicação da metodologia RP, bem como avaliaram os problemas aplicados nas turmas de Educação Básica.

Em um primeiro momento, foi realizado o aprofundamento conceitual sobre as obras dos autores que embasam nossa investigação sobre os aspectos epistemológico (Larry Laudan), pedagógico (John Dewey) e psicológico (Jerome Bruner) da RP. Na sequência, realizou-se um levantamento bibliográfico sobre a metodologia de RP e formação de professores. Com estes dois momentos de revisão bibliográfica, foram elaborados materiais para serem utilizados na formação.

O levantamento bibliográfico permitiu verificar que a RP se mostra adequada para o tratamento dos conteúdos de Ciências, por isso foi organizada uma proposta de curso de formação continuada na modalidade de extensão universitária, para oferecer aos professores elementos teóricos sobre a temática trabalhada.

Esse trabalho permitiu aos professores da Educação Básica um maior aprofundamento teórico em relação aos aspectos trabalhados e na elaboração de problemas, que passaram por diversas revisões dos pares e da equipe de professores. Além disso, os professores foram incentivados a aplicar os problemas nas suas aulas e discutir os resultados dessa implementação com seus colegas do grupo de formação.

A estrutura da proposta no curso de formação buscou certificar os aspectos das teorias que o sustentam e que foram trabalhadas durante o curso. Assim, as atividades visam o estabelecimento de uma base conceitual mínima, a partir da qual ocorre o aprofundamento e a contextualização. Isso ocorreu quando os exemplares dos problemas foram apresentados para os professores e, a partir daí eles elaboraram os seus próprios problemas que foram discutidos, negociados e reformulados no grupo de formação.

Nesse sentido, o curso de formação permitiu que o professor refletisse sobre as suas dificuldades conceituais, dificuldades pedagógicas, epistemologias e seu pouco preparo para 
orientar situações psicológicas do desenvolvimento humano. Nessa concepção, os módulos apresentados no curso de formação visaram a trabalhar teoricamente esses aspectos, para que o professor da Educação Básica consiga desenvolvê-los melhor ao longo de sua carreira.

Ademais, a experiência de vivenciar a atividade no papel de aluno favoreceu a compreensão dos professores sobre as possibilidades de aprendizagem da metodologia. Entre esses momentos, destacou-se a busca de materiais bibliográficos, a elaboração de hipóteses de trabalho e das resoluções para o problema proposto, assim como a apresentação das resoluções no formato de plenária, na qual foi realizada uma retomada de todas as modelações propostas pelo professor formador.

\section{Memórias do curso de formação}

Apresenta-se aspectos apreendidos durante as etapas do curso de formação. Esses foram analisados a partir dos registros do Diário de Campo das pesquisadoras e por meio dos depoimentos dos professores no decorrer da extensão universitária. Destaca-se o quanto a formação teórica trabalhada no Módulo I interferiu na produção e implementação da proposta metodológica de resolução de problemas nas aulas de Ciências.

No decorrer do curso de formação, cumpriu-se uma sequência organizativa para que os professores entrassem em contato com a proposta da RP. Para tanto, desenvolveu-se uma série de atividades com a intenção de trabalhar com esses professores tal metodologia. Dentre as atividades desenvolvidas, durante o primeiro módulo da formação, estavam questões teóricas. A primeira etapa do trabalho foi fortemente marcada pela apresentação e debate dos aspectos teóricos da metodologia da RP. Os professores realizaram leituras dirigidas, discussões e relações com a sua própria prática pedagógica. Algumas leituras foram feitas a partir de dinâmicas organizadas pelas professoras formadoras e com o uso de ferramentas como a elaboração de mapas conceituais, para verificar o entendimento dos professores sobre as leituras realizadas. O uso de dinâmicas de leitura e a produção de mapas conceituais para analisar e discutir os textos utilizados no curso motivou os cursistas e parece ter favorecido a apropriação dos pressupostos teóricos, como pode ser evidenciado nos discursos dos professores.

Outro aspecto identificado nos professores, durante o desenvolvimento do primeiro módulo do curso de formação, foi a capacidade de articularem os aspectos teóricos trabalhados no curso com a sua prática docente. Em muitas situações, quando os professores da equipe executora apresentavam os aspectos teóricos, muitos professores da Educação Básica relacionavam a teoria apresentada às situações de sua sala de aula. Esse aspecto se mostra 
bastante positivo na medida em que os professores conseguem articular os aspectos teóricos trabalhados na formação com a sua experiência docente.

Os aspectos teóricos desenvolvidos no curso de formação foram iniciados a partir de exemplares sobre RP que já haviam sido trabalhados na Educação Básica, inclusive aqueles já implementados pelo grupo de pesquisa (GOI; SANTOS, 2003, 2009, 2015, 2017; GOI, 2004). Parece que, ao saber que a proposta trabalhada no curso de formação já tinha sido implementada tanto na Educação Básica quanto em nível superior, ou até mesmo em outras áreas do conhecimento como no Direito, Medicina, Psicologia, os professores se sentem motivados a conhecê-la. Isso revela que trabalhar com uma proposta já validada em outros contextos faz com que os professores se sintam mais seguros para aplicá-la em suas situações de sala de aula.

Após a explanação dos exemplares sobre a RP, a equipe executora da formação propôs um problema da área de Ciências da Natureza ${ }^{2}$ para que os professores pudessem resolvê-lo e apresentar as suas soluções aos colegas (a resolução apresentada pelos professores aconteceu após uma semana de observação, análise e pesquisa do problema teórico-prático). Nesse momento, percebeu-se o quanto é importante que os professores resolvam situações-problema para que possam se familiarizar com a metodologia de RP. Realizada a resolução do problema, os professores formularam mais problemas a partir de enunciados de questões do Exame Nacional de Ensino Médio (ENEM). Essa primeira tentativa foi produtiva, pois os professores experienciaram o processo de resolução e produção de situações-problema.

A partir desse processo de apresentação da vivência de RP, iniciou-se a abordagem teórica relacionada ao tratamento epistemológico da RP evidenciado na literatura. Então, trabalhou-se sobre como a Ciência progride a partir do processo de RP apresentados por Larry Laudan. Além do tratamento teórico, oportunizou-se situações em que os professores fizessem uma articulação entre o aspecto teórico tratado e sua prática de sala de aula. Nesse momento, os professores fizeram emergir questões de seus contextos de sala de aula e perguntaram aos professores formadores se aquelas situações apresentadas se constituíam ou não em uma situação-problema. Nessa etapa do curso, percebeu-se que os professores da Educação Básica não conseguiam diferenciar exercícios de problemas e, por isso, a equipe executora teve que

\footnotetext{
${ }^{2}$ Problema aplicado junto ao grupo de formação de professores:

Ao preparar uma salada de frutas, Ana utilizou apenas a metade de uma maçã. A outra metade, ela deixou sobre a mesa enquanto cortava as demais frutas. Quando terminou o preparo da salada, ela percebeu que o pedaço da maçã que ficou sobre a mesa estava escuro.

a) O que fez a maçã ficar escura? Explique se o processo que aconteceu com a maçã é físico ou químico.

b) Ana ainda pode comer a maçã?

c) Como ela poderia ter evitado que a maçã ficasse escura?

d) O processo que ocorreu com a maçã, pode ocorrer com outras frutas? O que estas frutas têm em comum?
}

\# Tear: Revista de Educação Ciência e Tecnologia, Canoas, v.8, n.1, 2019. 
retomar os exemplares da literatura, pois os professores manifestaram dificuldades na compreensão das diferenças entre essas duas modalidades.

Em seguida, foram trabalhados os aspectos pedagógicos relacionados à RP. Para isso os professores formadores trabalharam os referencias de John Dewey. Percebeu-se que, ao tratar de questões pedagógicos, os professores se sentiram mais à vontade para relatar vivências de sua sala de aula. Foram levantados vários aspectos relacionados ao contexto da sala de aula. Dentre eles, destaca-se: Como trabalhar a experiência do aluno? Como articular um trabalho pedagogicamente orientado com situações instigantes a partir de um contexto no qual a Educação não é valorizada? Como produzir propostas que movimentem a comunidade escolar? Essas e outras questões foram discutidas a partir da perspectiva de John Dewey e se constituíram num verdadeiro e profícuo debate, articulando a teoria estudada e o contexto em que o professor da Educação Básica atua.

Ao tratar dos aspectos pedagógicos, percebeu-se a necessidade de trabalhar com as questões psicológicas relacionadas ao desenvolvimento da criança, por isso abordou-se os aspectos da teoria de Jerome Bruner. Nessa fase do curso de formação, foi constatada a carência conceitual que os professores têm para trabalhar os aspectos psicológicos na sala de aula. Os professores sinalizaram em suas falas que aspectos relacionados à teoria de Bruner estavam sendo trabalhados pela primeira vez. Os professores cursistas não conseguiram articular a teoria apreendida com o contexto de sua sala de aula, pois muitos estavam se aproximando e conhecendo esse referencial teórico.

Ao abordar aspectos da teoria psicológica que está relacionada diretamente com as fases do desenvolvimento da criança, percebeu-se que os professores tiveram que fazer um esforço cognitivo para compreender como acontece a construção do conhecimento científico na visão de Bruner. Esse fato reforça a nossa hipótese de que os professores carecem de conhecimento teórico relacionado ao aspecto psicológico de como acontece a produção do conhecimento humano. Abordando as fases do desenvolvimento da criança na concepção de Bruner, os professores da Educação Básica concordaram que pouco ou nada foi trabalhado na formação inicial relacionado a esse autor. Muitos dizem que esse aspecto não foi trabalhado e apresentado em programas de formação inicial ou em programas de formação continuada.

Outro dado importante que apareceu nos contextos de discussões está relacionado ao currículo em espiral. Verificou-se que os professores concordaram plenamente com as ideias de Bruner quando o autor diz que o conteúdo a ser trabalhado deve ser distribuído em progressão conceitual, porém sentiram dificuldades para tratar o conteúdo desta forma. Nesse 
sentido, os professores concordaram que os conteúdos trabalhados em sala de aula devem seguir uma sequência conceitual organizativa, da mais simples para a mais complexa, e esse conteúdo deveria voltar várias vezes para as questões fundamentais quando não fossem bem compreendidas pelos alunos. Porém, nessa fase de estudo teórico, quando o grupo de formação se encontrava parecia que os professores se davam conta de que muitos aspectos tratados na literatura não são percebidos e explorados nos contextos da sala de aula. Provavelmente, isso se deve ao pequeno contato dos professores com referenciais teóricos da psicologia. Os professores dizem que os aspectos psicológicos são muitas vezes tratados nos contextos acadêmicos de pós-graduação e não na formação inicial ou em formação continuada de professores, por isso a carência conceitual desse aporte teórico.

A partir desses apontamentos, acredita-se que as questões teóricas devem ser mais trabalhadas e articuladas nos contextos da formação inicial e continuada de professores. Os professores têm uma carência teórica que os cursos de formação inicial não conseguem superar, isso pelo fato de não terem tempo hábil para trabalhar a parte pedagógica, psicológica, epistemológica e específica de sua formação no tempo da graduação. Por isso se faz necessária a formação continuada de professores na tentativa de trabalhar com aspectos que a formação inicial não consegue contemplar com aprofundamento e qualidade necessários.

Na socialização das propostas de problemas, a equipe de professores formadores e os colegas de curso propunham sugestões de melhorias para os enunciados e atividades. Dessa forma, diversos problemas foram otimizados nessa etapa do trabalho, além de evidenciar as possibilidades de adaptação dos enunciados para as necessidades educativas de cada disciplina ou nível de ensino. Esse momento de discussão favoreceu o entendimento do grupo sobre as diferentes formas de estruturação dos enunciados, fontes de materiais de referência e possibilidades de atividades a serem realizadas nos problemas. Além disso, a atividade contribuiu para desenvolver a habilidade de elaboração dos enunciados, uma das maiores dificuldades enfrentadas pelos professores.

\section{Os Problemas produzidos no curso de formação}

A seguir, apresenta-se e analisa-se exemplares dos problemas elaborados pelo grupo de formação, conforme as categorias descritas na literatura. Para a preservação da identidade pessoal e profissional, os docentes são, então, denominados pela letra D seguida da sequência 
numérica do 1 ao $18^{3}$. Os problemas apresentados estão organizados em módulos e em ordem alfabética, seguindo uma sequência numérica.

Quadro 1- Problemas produzidos pelos professores em curso de formação

\begin{tabular}{|c|c|}
\hline Docentes & loco de problemas \\
\hline D1 e D2 & $\begin{array}{l}\text { Bloco A- } \\
\text { P1-O desenvolvimento tecnológico traz embutido diversas consequências danosas. O homem cria } \\
\text { inúmeras formas e alternativas de buscar resultados mais eficientes a menores custos. Muitas vezes não } \\
\text { dimensiona o resultado de suas atitudes e não têm uma visão global do mundo em função dos prós e } \\
\text { contras, problema que causa direta ou indiretamente danos ao meio ambiente. } \\
\text { O que você entende por 'Problema Ambiental'? Quais as principais causas? } \\
\text { P2-Os problemas ambientais estão cada vez se amplificando e se tornando rotineiros em nossa vida. } \\
\text { Muitas indústrias não tratam seus resíduos e despejam em rios produtos químicos, causando poluição e } \\
\text { mortandade de peixes. As pessoas sujam as ruas, o que provoca o entupimento de bueiros, resultando } \\
\text { em alagamentos, quando chove. Essa situação pode provocar problemas no transporte e doenças como } \\
\text { a leptospirose, além de outros. } \\
\text { Escolha um problema ambiental da sua cidade e especule sobre o que pode tê-lo ocasionado. } \\
\text { Relacione a Química com esse problema. } \\
\text { P3-A solução para os problemas ambientais está em promover uma melhor organização da cidade e } \\
\text { também na informação e educação ambiental para a população, promovendo a integração da } \\
\text { comunidade em busca de melhores condições junto às autoridades para solucionar os problemas da } \\
\text { mesma. } \\
\text { Que soluções você propõe para resolver ou minimizar o problema ambiental da sua cidade? }\end{array}$ \\
\hline D3 & $\begin{array}{l}\text { Bloco B } \\
\text { P4-A ciência que estuda as interações dos seres vivos entre si e com o ambiente é chamada de Ecologia. } \\
\text { Para compreendermos melhor o estudo da Ecologia temos alguns conceitos muito importantes, um deles } \\
\text { é ECOSSISTEMA. Ecossistema é o conjunto formado pelos seres vivos e o ambiente em que eles } \\
\text { vivem, incluindo suas relações. Os ecossistemas apresentam características próprias, diferenciando-se } \\
\text { quanto aos fatores ambientais e aos seres vivos existentes no local. } \\
\text { Sabendo disso, através de estudo de campo, podemos entender, na prática, como funciona um } \\
\text { ecossistema. Se você analisar algum ambiente natural, é possível relacionar com um ecossistema? } \\
\text { Observe detalhadamente um ambiente natural próximo de sua casa e descreva-o. Que tipo de } \\
\text { ecossistema foi encontrado? } \\
\text { P5-Os fungos são seres heterótrofos, ou seja, incapazes de produzir seu próprio alimento. Nos fungos a } \\
\text { digestão é extracorpórea, ou seja, é realizada fora do corpo. O fungo lança no ambiente enzimas que } \\
\text { degradam as moléculas orgânicas complexas e depois, absorve moléculas menores, mais simples. A } \\
\text { principal atividade dos fungos é a decomposição da matéria orgânica, a qual é de extrema importância } \\
\text { para manutenção dos ecossistemas. } \\
\text { Imagine-se como um cientista e demonstre através de um experimento o surgimento de fungos em } \\
\text { seu dia a dia. Observe seu experimento todos os dias, fotografe, faça suas anotações e conclua. } \\
\text { Quais as condições ideais para o desenvolvimento dos fungos? } \\
\text { O que aconteceria se os fungos fossem extintos? }\end{array}$ \\
\hline D5 & $\begin{array}{l}\text { Bloco C } \\
\text { P6-No rótulo de algumas margarinas observamos a expressão: } 0 \% \text { de gordura trans. } \\
\text { Do ponto de vista da química, como é caracterizada uma gordura trans e quais os efeitos do } \\
\text { consumo desse tipo de gordura em nosso organismo. } \\
\text { P7-Você já deve ter observado, em algumas marcas de margarina vendidas em supermercados, a } \\
\text { seguinte indicação: rica em poli-insaturados. Apesar de as moléculas das gorduras vegetais que entram } \\
\text { na composição dessas margarinas pertencerem à outra função orgânica, suas longas cadeias carbônicas } \\
\text { contém mais de uma insaturação, daí a denominação poli-insaturados. Esta mesma indicação não é } \\
\text { encontrada em rótulos de manteiga. } \\
\text { Pesquise a diferença química entre margarina e manteiga mostrando qual é a mais saudável para } \\
\text { nosso consumo e proponha um experimento para identificar essa diferença. }\end{array}$ \\
\hline
\end{tabular}

\footnotetext{
${ }^{3} \mathrm{O}$ número de sujeitos reduziu de 24 para 18 porque nem todos os professores elaboraram os problemas e os implementaram em suas salas de aula.
} 


\begin{tabular}{|c|c|}
\hline Docentes & Bloco de problemas \\
\hline $\begin{array}{l}\text { D6, D7, } \\
\text { D8 }\end{array}$ & 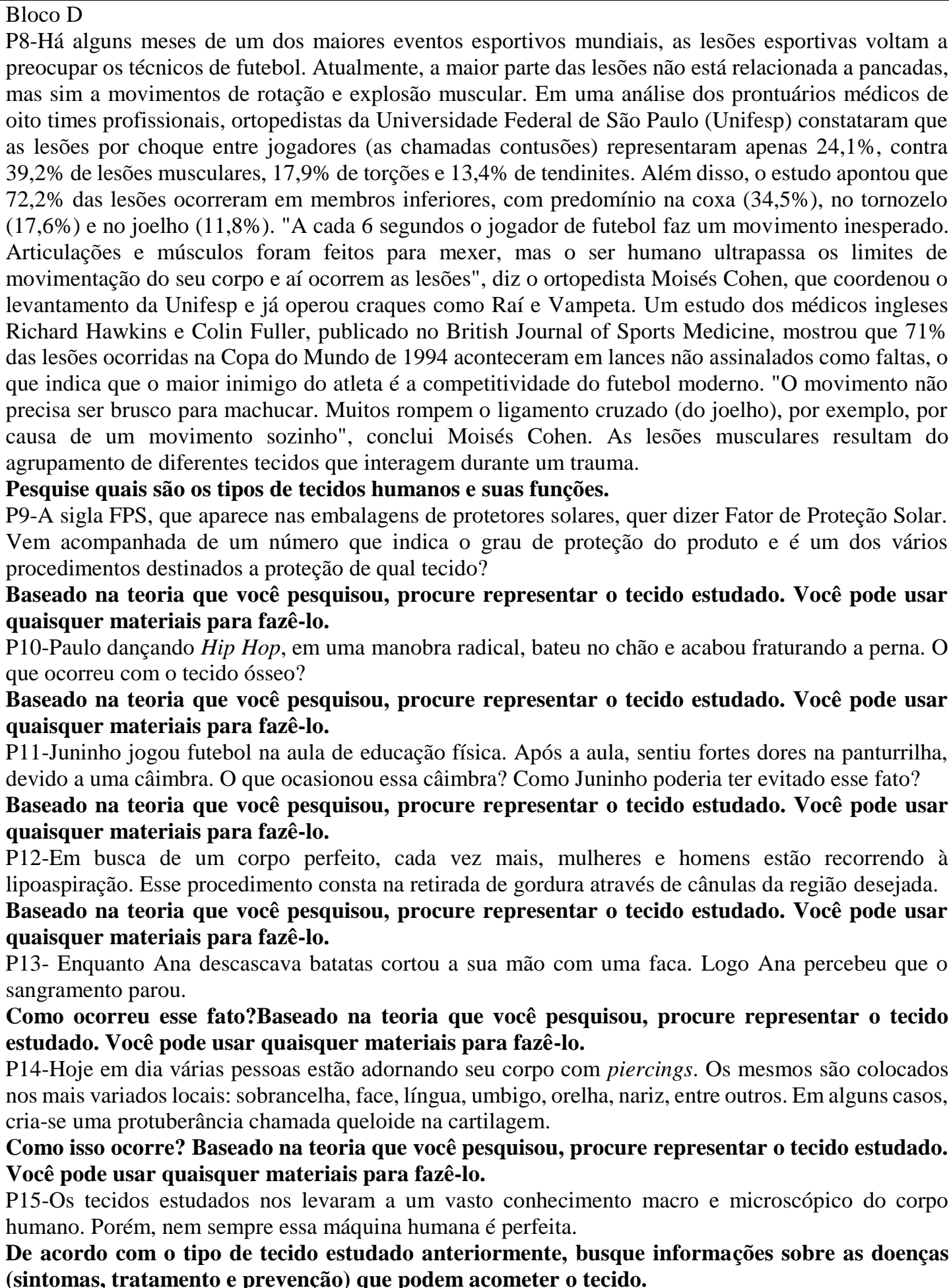 \\
\hline D9 & $\begin{array}{l}\text { Bloco } \mathrm{E} \\
\text { P16-Verificou-se que os impactos ambientais, termo bastante utilizado atualmente, podem ser } \\
\text { ocasionados de várias maneiras e por várias atividades. Nota-se que eles sempre existiram, naturalmente } \\
\text { ou não. } \\
\text { Obviamente que o impacto humano sobre o ambiente até os dias de hoje constitui-se em uma } \\
\text { parcela muito maior, quando comparada aos impactos naturais. Diante disso, pesquise sobre os } \\
\text { tipos de problemas ambientais existentes no País que sua turma está trabalhando. }\end{array}$ \\
\hline
\end{tabular}




\begin{tabular}{|c|c|}
\hline Docentes & Bloco de problemas \\
\hline & $\begin{array}{l}\text { P17-O Homem necessita rever seu modo de vida, fazer novas escolhas, que contribuam para a redução } \\
\text { do impacto humano individual e social no planeta. Pensando nisso, como a cultura interfere nestas } \\
\text { questões? } \\
\text { P18-Que tipo de atitudes o homem pode ter para diminuir esses impactos e amenizar os problemas } \\
\text { gerados no convívio ambiental? }\end{array}$ \\
\hline D10 & 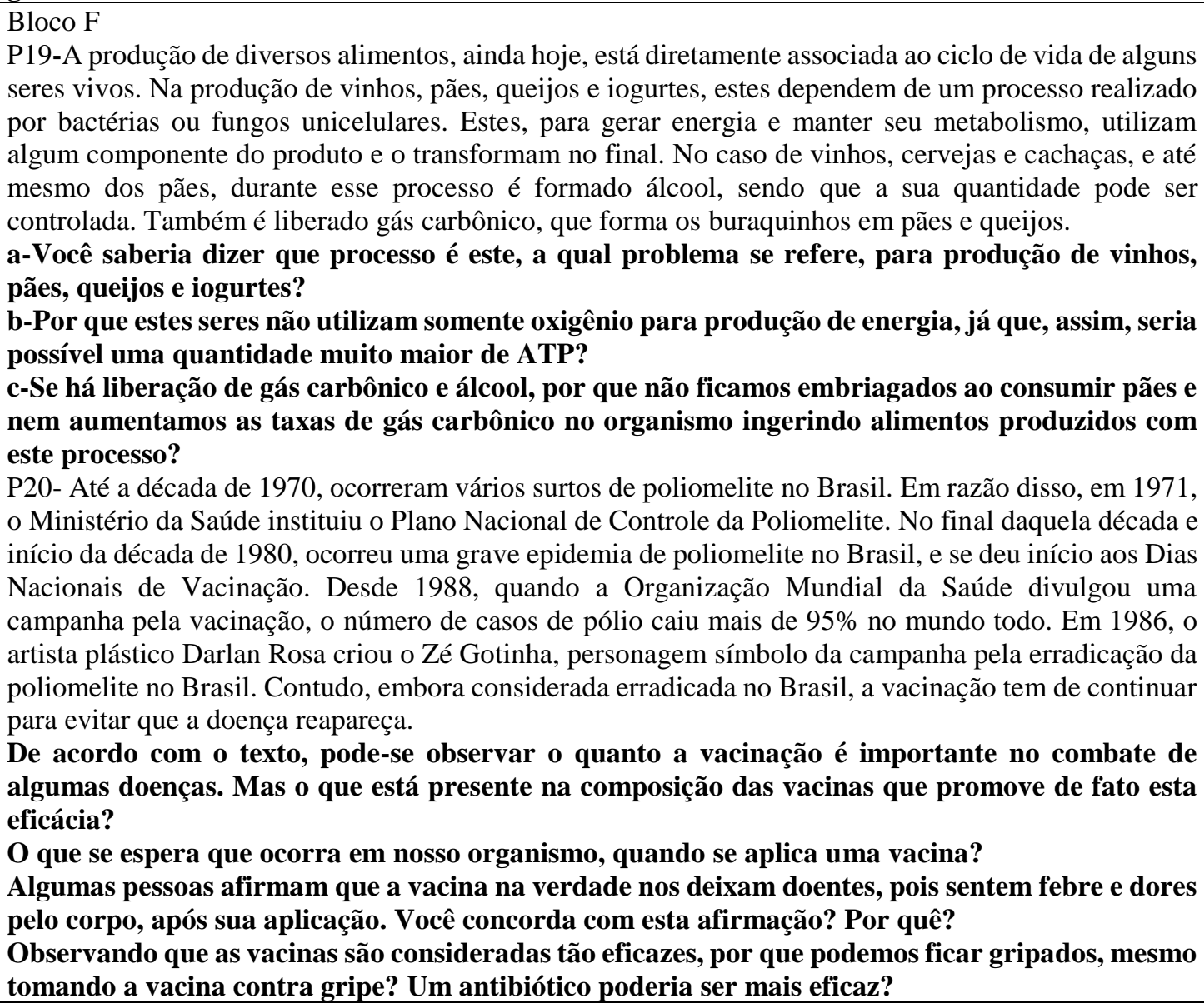 \\
\hline D11 & $\begin{array}{l}\text { Bloco G } \\
\text { P21- Separação de mistura de areia e sal } \\
\text { Na natureza é raro encontrarmos substâncias puras, normalmente encontramos misturas de substâncias, } \\
\text { e muitas vezes essas misturas não possuem grandes utilidades. A água do mar é um exemplo de uma } \\
\text { mistura de água com vários sais dissolvidos que não possui muita serventia, entretanto, se evaporarmos } \\
\text { a água, nós obtemos o sal, com grande utilidade no nosso dia a dia. Imagine uma pessoa que não tem } \\
\text { acesso à água do mar, mas consegue uma grande quantidade de uma mistura de areia e sal. Explique } \\
\text { como essa pessoa pode obter sal puro a partir dessa mistura, identificando os processos e materiais } \\
\text { utilizados. } \\
\text { P22- Tratamento de água } \\
\text { A água é um recurso renovável pelo ciclo natural evaporação - chuva e distribuído com fartura na maior } \\
\text { parte da superfície do planeta. Acontece que a ação humana afetou de forma decisiva a renovação natural } \\
\text { dos recursos hídricos. Estima-se que } 50 \% \text { dos rios do mundo estejam poluídos por esgotos, dejetos } \\
\text { industriais e agrotóxicos. Para que tenhamos água potável para consumirmos ela passa por tratamento. } \\
\text { Pesquise as etapas do tratamento da água e diga quais são métodos de separação de misturas, } \\
\text { justificando. }\end{array}$ \\
\hline $\mathrm{D} 12$ e 13 & $\begin{array}{l}\text { Bloco H } \\
\text { P23- Na Copa do Mundo de } 2014 \text { no Brasil, a FIFA tem uma missão clara: manter o futebol livre do } \\
\text { dopping. Para isso, a FIFA anunciou no dia } 1^{\circ} \text { de março, em São Paulo, que todos os jogadores que irão } \\
\text { disputar a Copa do Mundo deste ano serão submetidos em algum momento a um teste antidopping } \\
\text { surpresa. O antidopping é um exame realizado para saber se o atleta ingeriu alguma substância proibida. } \\
\text { Os testes serão realizados com amostra da urina ou sangue. Existem alguns tipos de substâncias } \\
\text { proibidas, como os estimulantes, calmantes, diuréticos, esteroides e anabolizantes, que, mesmo em }\end{array}$ \\
\hline
\end{tabular}




\begin{tabular}{|c|c|}
\hline Docentes & 3loco de problemas \\
\hline & 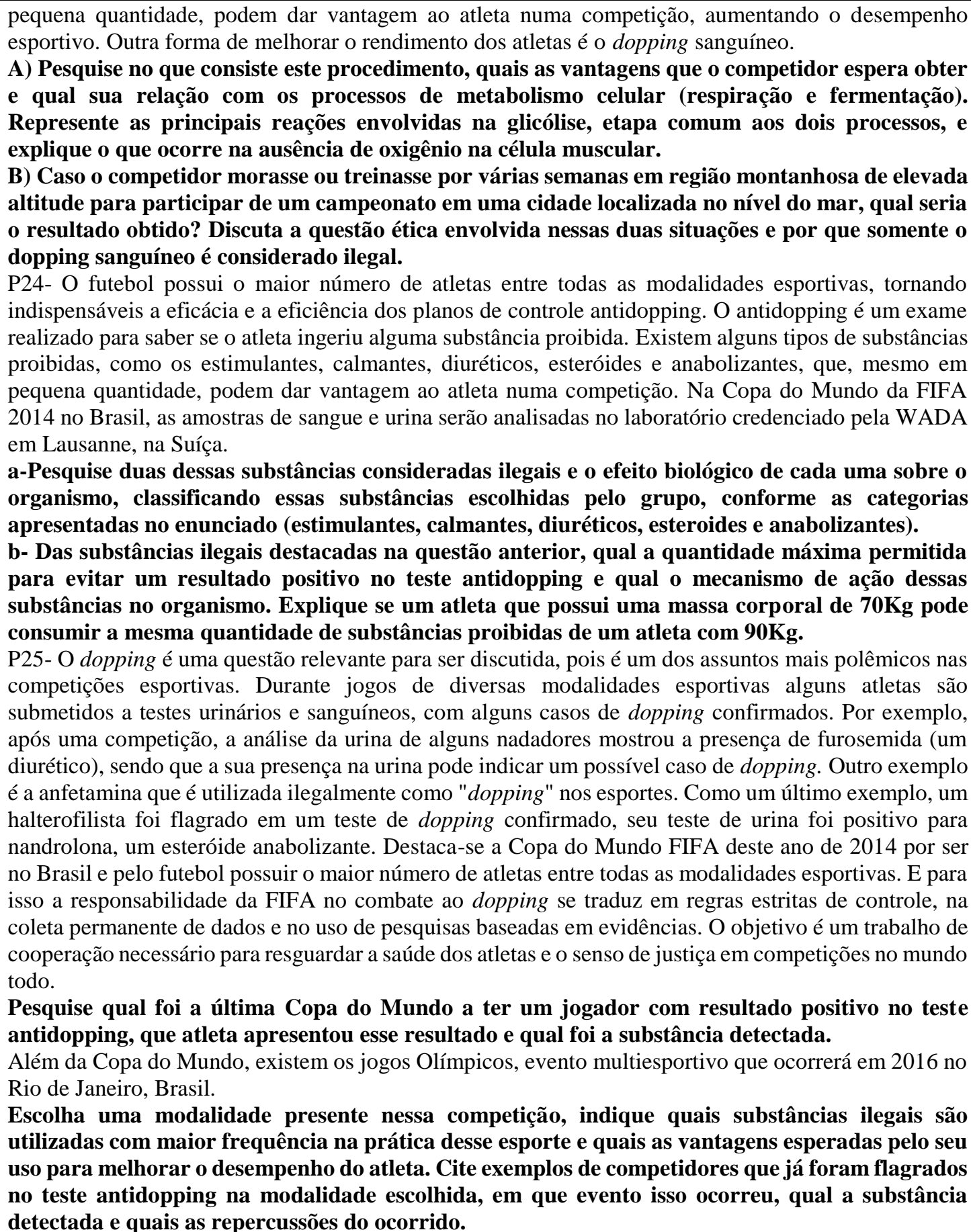 \\
\hline D14 & $\begin{array}{l}\text { Bloco I } \\
\text { P26- Após a queda do homem em pecado, Deus fala a Adão e Eva: "Por causa do que você fez, a terra } \\
\text { será maldita. Você terá de trabalhar duramente a vida inteira a fim de que a terra produza alimento } \\
\text { suficiente para você (...). Isto até que você volte à terra, pois dela você foi formado. Você foi feito de } \\
\text { terra e vai virar terra outra vez". Gênesis } 2.17-19 \text {. } \\
\text { A vida do ser humano e sua relação com o meio ambiente sofreu graves consequências após a queda } \\
\text { em pecado. Uma dessas consequências foi a tarefa de cultivar a terra para obter alimento. } \\
\text { Qual a origem dos alimentos consumidos pelos seres humanos? Como são classificados? } \\
\text { P27- No relato de Gênesis, podemos observar que a família de Adão e Eva, provavelmente, consumia } \\
\text { alimentos de origem animal e vegetal. Seus filhos trabalhavam em diferentes tipos de atividades: Caim } \\
\text { era agricultor e Abel era pastor de ovelhas. }\end{array}$ \\
\hline
\end{tabular}




\begin{tabular}{|c|c|}
\hline Docentes & Bloco de problemas \\
\hline & $\begin{array}{l}\text { Você já deve ter ouvido alguém falar que é importante "comer de tudo um pouco", e que alguns tipos } \\
\text { de alimentos são muito importantes para crianças e adultos. } \\
\text { O que é uma alimentação saudável? Organize, em sala de aula, uma apresentação sobre o assunto. } \\
\text { P28- O ser humano é capaz de perceber sabores e odores diferentes nos alimentos. A estes sentidos } \\
\text { chamamos de "paladar" (sentir o gosto) e "olfato" (sentir o cheiro), esses são muito importantes na hora } \\
\text { de escolhermos o que vamos comer. } \\
\text { Proponha um experimento para demonstrar a nossa percepção dos sabores ou odores dos } \\
\text { alimentos. }\end{array}$ \\
\hline D15,16 & $\begin{array}{l}\text { Bloco J } \\
\text { P29-As drogas estão classificadas em lícitas, liberadas o uso por lei, e ilícitas, não liberadas. As lícitas, } \\
\text { como, por exemplo, o álcool, são utilizadas em "massa" por adolescentes, muitas vezes menores de } \\
\text { idade, em reuniões de amigos e festas. Segundo Içami Tiba (2007), os adolescentes que fazem uso } \\
\text { abusivo de álcool acabam por experimentar maconha, abrindo as "portas" para as drogas ilícitas. } \\
\text { O que motiva os adolescentes de } 15 \text { a } 18 \text { anos a usarem drogas? E na sua cidade, quais as drogas } \\
\text { mais utilizadas entre os jovens? } \\
\text { P30- Quando fazemos uso de drogas, liberamos no organismo diferentes neurotransmissores que agem } \\
\text { no SNC (sistema nervoso central), modificando o comportamento de quem as usa. } \\
\text { Como essas drogas podem liberar no SNC substâncias químicas produzidas por neurônios? } \\
\text { Usando como parâmetro as drogas pesquisadas no problema anterior, quais os } \\
\text { neurotransmissores liberados por elas, durante o uso, e como agem no SNC? } \\
\text { P31- Do ponto de vista químico, podemos classificar as substâncias orgânicas levando em consideração } \\
\text { os grupos funcionais presentes na sua molécula. As drogas e os neurotransmissores são compostos } \\
\text { orgânicos formados por variadas funções. } \\
\text { Nas drogas do PI, quais as funçôes que estão presentes? Estas funções influenciam a ação destas } \\
\text { drogas no organismo? De qual forma? }\end{array}$ \\
\hline D17,18 & 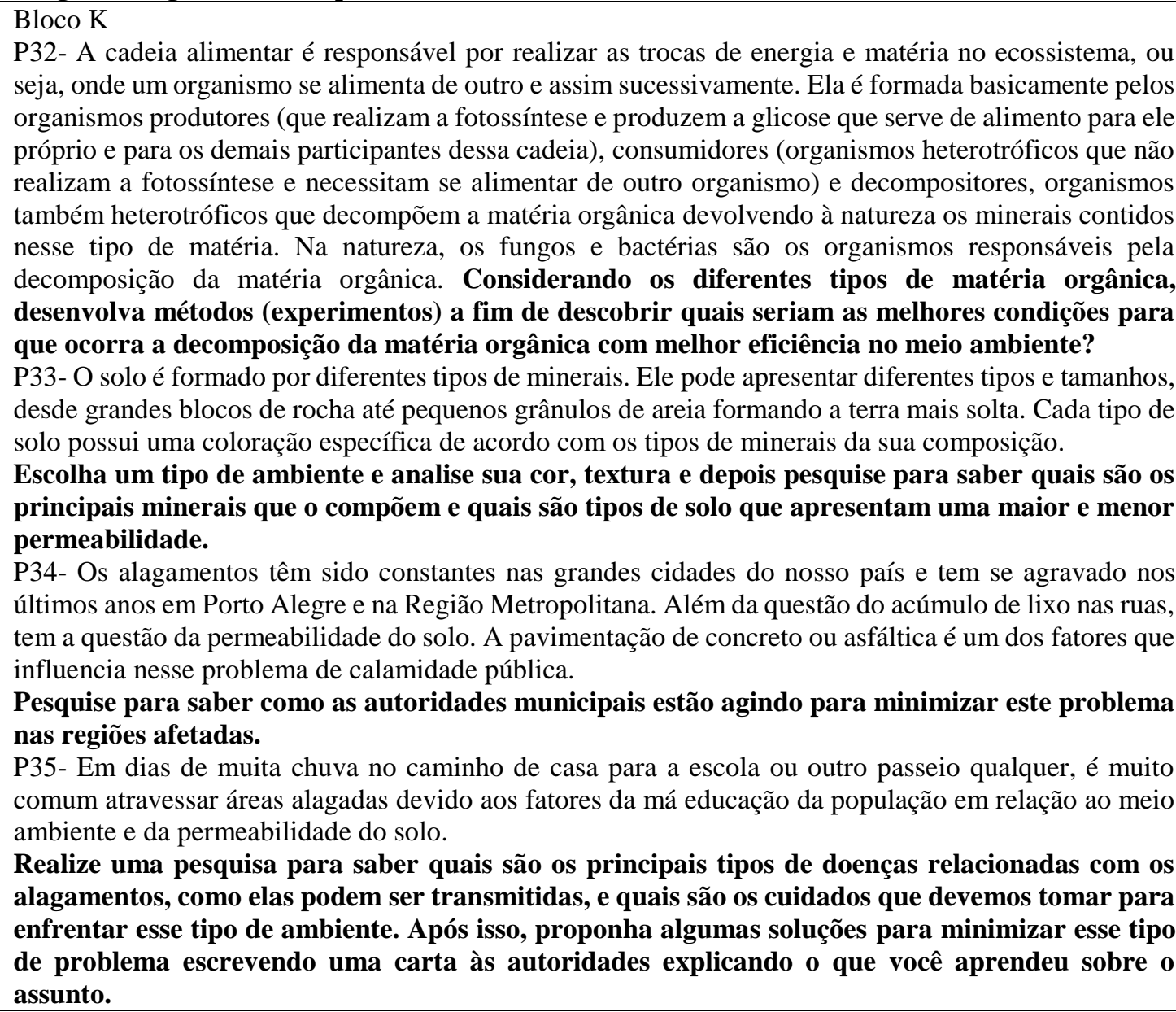 \\
\hline
\end{tabular}

Fonte: GOI (2014). 
As trinta e cinco situações produzidas pelos professores são da área das Ciências da Natureza. Seis situações-problema tratadas de forma interdisciplinar entre as disciplinas de Química, Biologia e Física (P23, P24, P25) e Biologia e Ensino Religioso (P26, P27, P28). As demais foram incluídas nas áreas de Ciências Biológicas (P4, P5, P8, P9, P10, P11, P12, P13, P14, P15, P19, P20, P32, P33, P34 e P35) e de Química (P1, P2, P3, P6, P7, P16, P17, P18, P21, P22, P29, P30 e P31).

Em relação aos conteúdos curriculares e temas transversais tratados em cada situaçãoproblema, das trinta e cinco situações analisadas, pode-se identificá-las como: situações sobre questões ambientais (P1, P2, P3, P4, P16, P17, P18, P34, P35), problemas tratando de química orgânica (P5, P6, P7, P31, P32), corpo humano (P8, P9, P10, P11, P12, P13, P14, P15 P20, P28), produção de energia-ATP (P19), substâncias, misturas de substâncias e processos de separação de misturas (P21, P22), dopping esportivo (P23, P24, P25), alimentos (P26, P27), drogas - composição, neurotransmissores, danos ao organismo (P29, P30, P31) e solo (P33).

Ao analisar as dicotomias dedutivo e não dedutivo, que se referem ao tipo de raciocínio que o indivíduo deve acionar na resolução de um problema, pode-se dizer que as trinta e cinco situações apresentadas são do tipo indutiva e uma parte de um dos problemas (P24) pode ser parcialmente classificada como indutiva (porque é necessário utilizar apenas uma fórmula matemática para resolver a dada situação) e parcialmente do tipo dedutivo.

Em relação à dicotomia definido e indefinido, relativa à resolução ou não do problema, identifica-se que apenas $3 \%$ dos problemas podem ser classificados como tipo indefinido. Apenas o exemplar P7 foi um problema de difícil solução. Isso foi comprovado não apenas nos comentários de validação dos problemas realizados no curso de formação, mas também durante a resolução dessa situação pelos estudantes. Muitos alunos não conseguiram chegar a uma solução sem o auxílio do professor (D5).

Os problemas também podem ser classificados como escolares, científicos ou problemas que levam em consideração as questões do cotidiano. Das trinta e cinco situações-problema, a maioria delas está classificada como problemas escolares (P4, P5, P6, P7; P8; P9, P10, P11, P12, P13, P14, P15, P16; P17; P18; P19, P21, P26, P27, P28, P30, P31, P32, P33), nenhuma como problema científico e a minoria como problemas do cotidiano (P1, P2, P3, P34, P35). Ainda pode-se identificar outra categoria que está relacionada aos conteúdos escolares e com as questões do cotidiano (P20, P22, P23, P24 e P29). 
As situações analisadas são na maioria problemas abertos, para os quais encontra-se mais de uma resposta durante a resolução da situação. Os problemas P7, P8, P9, P10, P11, P12, P13, P14, P26, P31, P32 são classificados como problemas fechados.

Os professores elaboraram os problemas e durante a sua implementação e os entregaram para os alunos por escrito, por isso foram classificados como formais. Na resolução dos problemas, parece que a maioria dos alunos teve assessoria dos professores durante a implementação da proposta, ou seja, os professores se fizeram presentes e atuantes no momento da resolução de cada situação.

Os problemas tratados nesta análise são reais ou artificiais. Alguns deles foram elaborados de acordo com a realidade na qual seria implementada, outros foram elaborados de acordo com o currículo trabalhado em cada contexto da Educação Básica. Das trinta e cinco situações elaboradas, dezessete foram organizadas pensando na realidade do grupo em que esses problemas foram aplicados (P1, P2, P3, P9, P10, P11, P12, P13, P14, P15, P18, P20, P27; P29; P30; P31; P35). Os demais foram problemas artificiais, classificados de acordo com o conteúdo escolar da série ou ano em que foram implementados.

Em relação à natureza dessas situações-problema, pode-se organizá-las de acordo com a natureza teórica, experimental ou teórica versus experimental. Das trinta e cinco situações apresentadas, a maioria delas é de natureza teórica, relacionada a algum experimento (P4, P5, P7, P21, P22, P28, P32; P33), e nenhuma delas de natureza puramente experimental.

A categorização dos problemas apresentada por Lopes (1994); Pozo (1998); Watts (1991) e outros autores permite que possa se fazer uma análise das situações elaboradas pelos professores em relação à escolha da natureza de cada problema. Das situações-problema analisadas, pode-se identificar que os professores têm preferência em formular problemas de linha teórica, poucos têm habilidades para organizar situações práticas ou teórico-práticas. Isso parece indicar que os professores não demonstram intenção de elaborar problemas que possam ser utilizados no laboratório didático, talvez pelo fato de nas instituições escolares haver pouco recurso de laboratório ou pela carência de tempo do professor para cumprir o currículo mínimo do ano ou série em que está trabalhando.

Outro ponto a ser considerado relaciona-se à tendência dos professores para elaborar problemas de acordo com o conteúdo curricular e nenhum deles propôs problemas nãocurriculares. Isso reforça o fato dos professores não produzirem problemas científicos, o que demonstra a preocupação dos professores em relação aos conteúdos curriculares apresentados nos planos de ensino. 
Os problemas elaborados pelos professores se constituíram, na maioria, em blocos sequenciais e foram aplicados na Educação Básica. Por serem organizados em blocos, levaram um maior período de tempo para serem implementados nas escolas. Observa-se que apenas os problemas P19 e P20 foram construídos de forma unitária, ou seja, esses dois problemas não estavam relacionados entre si, um trata do conteúdo de produção de energia-ATP e outro sobre as vacinas.

A dinâmica de implementação ocorreu por um período de tempo de, pelo menos, um mês de aplicação. Como já comentado, isso aconteceu devido ao fato de os professores não terem elaborado apenas um problema, mas um conjunto de situações-problema, blocos de problemas. Esse fato foi favorável à medida em que a literatura nos mostra que a implementação do trabalho com RP não deve ser esporádica, mas deve manter uma rotina de resolução usada de forma extensiva para que os alunos e professores consigam se organizar de forma a resolver cada situação através de uma sequência didática (POZO, 1998).

Além do fato de os problemas estarem organizados em blocos e de serem implementados por um maior período de tempo na Educação Básica, deve-se considerar que os professores em formação produziram os problemas considerando que esses deveriam iniciar por situações mais simples e, ao longo do processo, ir aumentando o grau de dificuldades conceituais. Isso é comprovado em várias situações, como, por exemplo, nos problemas P21 e P22 em que se inicia a situação comentando sobre substância e misturas de substâncias e no problema seguinte a situação é conduzida para os processos de separação de misturas. Observase que há uma gradação das dificuldades apresentadas do P21 para o P22. Outro exemplar que demonstra a gradação das dificuldades conceituais dos problemas está apresentada no P29 para o P30 e P31 que inicia contextualizando o tema "drogas", insere-se a questão da liberação dos neurotransmissores acionados pela ação das drogas no corpo humano e solicita-se, aos alunos, a identificação de compostos orgânicos presentes nas drogas. Observa-se uma ampliação de dificuldades conceituais em cada uma das situações-problema. Parece que os professores tiveram o cuidado de partir de situações mais simples para as mais complexas e se preocuparam em criar situações para o aluno elaborar suas hipóteses e descobrir a partir do seu próprio processo de busca (pesquisa), assim o estudante ganha autoconfiança e amplia o seu interesse pelo estudo da matéria.

Pode-se dizer que o professor fez uso do referencial teórico trabalhado no curso de formação e elaborou os problemas valorizando os níveis de desenvolvimento dos estudantes. 


\section{\#tear}

Bruner (1966, p.15) destaca que "[...] a aprendizagem escolar cria habilidades que mais tarde se transformam em atividades."

\section{Considerações Finais}

Com o presente relato de experiência, verifica-se que o processo formativo implementado parece ter possibilitado aos professores elementos teóricos sobre a metodologia de RP, no que tange os aspectos pedagógicos, epistemológicos e psicológicos. É pertinente salientar que, durante as discussões e dinâmicas de leituras realizadas nas aulas, os professores demonstraram ter se apropriado dos aportes teóricos trabalhados. Dessa forma, infere-se que as atividades formativas e a carga-horária foram apropriadas para contemplar os objetivos do curso quanto à aprendizagem de conhecimentos conceituais.

Os professores apresentaram algumas dificuldades conceituais durante o aprofundamento teórico adotado no curso de formação. Nesse sentido, evidencia-se a necessidade de fornecer aos professores da Educação Básica um aprofundamento conceitual e metodológico para melhorar a qualidade de suas aulas de Ciências. Pouco ou nada adianta fornecer aos professores cursos que trabalhem com receitas produzidas por terceiros, uma vez que o fenômeno educativo é complexo e singular. Deve-se investir em programas nos quais o professor assuma o compromisso com a reflexão do seu trabalho docente e que possa aprofundar seus conhecimentos conceituais e metodológicos de forma que sua práxis seja transformada positivamente.

Essa investigação fortaleceu o que este grupo de pesquisa vem investigando há mais de 15 anos nas formações de professores, no que se refere às carências teóricas que os professores enfrentam para trabalhar em suas aulas de Ciências. É visível o quanto os educadores utilizam basicamente estratégias do ensino tradicionais, talvez pela ausência ou superficialidade da formação dos professores, relacionadas a outras propostas de ensino. Parece que urge desacomodar uma vastidão de conhecimentos e crenças visando à introdução de novos e desafiadores saberes para tais educadores. 


\title{
METHODOLOGICAL ASPECTS OF THE PROBLEM-SOLVING METHODOLOGY IN THE TRAINING OF TEACHERS OF NATURAL SCIENCES
}

\begin{abstract}
In this work we report an experience in the training of teachers of natural sciences that aims to deepen the conceptual and methodological aspects of Problem-Solving Methodology. For this purpose, we sought to dialogue with different educational theoretical references of the epistemological, pedagogical and psychological fields. Aspects seized during the stages of the training course are discussed. The records of the diaries and field notes of the researchers and the testimonials of the teachers during the training were analyzed. The experience gained and the data obtained indicated that the development of skills in the problemsolving process can be carried out in the course of training, and permitted, as well, to raise a series of issues regarding teacher training. Thus, it is understood that this process is a complex task especially when it comes to the practical-reflexive training and the expansion of didactic abilities and strategies in what concerns the production and use of teaching materials.
\end{abstract}

Keywords: Teacher Education. Science Education. Problem Solving. Methodology.

\section{Referências}

BOLZAN, E. C. V. M. M. Resolução de Problemas como proposta para o ensino e aprendizagem de Física Moderna e Contemporânea no ensino médio. 2015. Trabalho de Conclusão (Graduação) - Universidade Federal do Pampa, Caçapava do Sul/RS, 2015.

BOLZAN, T. D. Ensino da Função Polinomial do $2^{\circ}$ Grau através da metodologia da resolução de problemas. 2015a. Trabalho de Conclusão de Curso (Graduação) Universidade Federal do Pampa, Caçapava do Sul/RS, 2015a.

BORGES, P. B. P. Investigando sobre a formação continuada de professores na rede pública de ensino do Estado do Rio Grande do Sul. 2018. Trabalho de Conclusão de Curso (Especialização em Educação Científica e Tecnológica) - Universidade Federal do Pampa, Caçapava do Sul/RS, 2018.

BENTLIN, F. R. S. Resolução de problemas como prática de ensino sobre funções inorgânicas para alunos da EJA. 2009. Trabalho de Conclusão de Curso (Graduação) Instituto de Química, Universidade Federal do Rio Grande do Sul, Porto Alegre, 2009.

BRUNER, J. S. Uma nova teoria da aprendizagem. Rio de Janeiro: Block Editores, 1966.

FREITAS, J.Q.P. Resolução de problemas no ensino da Matemática: uma introdução à geometria fractal no ensino fundamental. 2015. Trabalho de Conclusão de Curso (Graduação em Ciências Exatas) - Universidade Federal do Pampa, Caçapava do Sul/RS, 2015.

GOI, M.E.J. A Construção do conhecimento químico por estratégias de resolução de problemas. 2004. 151f. Dissertação (Mestrado em Ensino de Ciências e Matemática) Universidade Luterana do Brasil, Canoas, 2004. 
GOI, M.E.J. Formação de professores para o desenvolvimento da metodologia de resolução de problemas na educação básica. 2014. 267f. Tese (Doutorado em Educação) Universidade Federal do Rio Grande do Sul, Porto Alegre, 2014.

GOI, M. E. J.; SANTOS, F. M. T. A Construção do Conhecimento Químico por Estratégias de Resolução de Problemas. In: ENCONTRO NACIONAL DE PESQUISA EM EDUCAÇÃO EM CIÊNCIAS, 4., 2003, Bauru. Atas ... Bauru, ABRAPEC, 2003. p.1-12.

GOI, M. E. J.; SANTOS, F. M. T. Reações de Combustão e Impacto Ambiental por meio de Resolução de Problemas e Atividades Experimentais. Química Nova na Escola, v. 31, p. 203-209, 2009.

GOI, M. E. J.; SANTOS, F. M. T. Produção de Situações-problema na Formação continuada de professores de Ciências. In: ENCONTRO NACIONAL DE PESQUISA EM EDUCAÇÃO EM CIÊNCIAS, 10., 2015, Águas de Lindóia. Atas... Águas de Lindóia, ABRAPEC, 2015.p.1-8.

GOI, M. E. J.; SANTOS, F. M. T. Formação de professores de ciências: Formação para o uso de situações-problema. Experiências em Ensino de Ciências, v.12, p.290 - 309, 2017.

LEITE, S. B Estudo sobre polímeros através da resolução de problemas. 2009.Trabalho de Conclusão de Curso (Graduação) - Universidade Federal do Rio Grande do Sul, Instituto de Química, Porto Alegre, 2009.

LEITE, S. B. Fórum Estadual Permanente de Apoio à Formação Docente do Rio Grande do Sul: Plano Estratégico de Formação de Professores do Estado. 2013. Dissertação (Mestrado em Educação) - Universidade Federal do Rio Grande do Sul, 2013.

LOPES. B. J. Resolução de problemas em Física e Química: modelo para estratégias de ensino-aprendizagem. Lisboa: LDA, 1994.

MENEZES, P. D.;GOI, M. E. J.; SILVA, E. R. A. ; VIVIAN, M. F.;BORGES, P. B. P . Formação continuada de professores: um estudo em coordenadorias regionais de Educação do RS. In: SIEPE - SALÃO INTERNACIONAL DE ENSINO, PESQUISA E EXTENSÃO, 9., 2017, Santana do Livramento. Anais...Santana do Livramento: UNIPAMPA, 2017. p. 1-5.

LÜDCKE, M.; ANDRÉ, M. Pesquisa em Educação: abordagens qualitativas. São Paulo: EPU, 1986.

PERES, R. G. Análises e reflexões sobre o uso da resolução de problemas como alternativa metodológica para o ensino de química no ensino técnico. 2015. Trabalho de Conclusão de Curso (Graduação) - Universidade Federal do Rio Grande do Sul, Instituto de Química, Porto Alegre, 2015.

PORLÁN A. R.; MARTÍN, J. El diario del profesor: un recurso para la investigación en el aula. 6. ed. Sevilla: Díada, 1998.

POZO, J. I. (org.) A Solução de Problemas: aprender a resolver, resolver para aprender. Porto Alegre: Artmed, 1998. 
SANTOS, A. B. Resolução de problemas como prática de ensino de funções inorgânicas. 2009. Trabalho de Conclusão de Curso (Graduação) -Universidade Federal do Rio Grande do Sul. Instituto de Química, Porto Alegre, 2009.

SANTOS, F. M. T.; GOI, M. E. J. Resolução de problemas e atividades práticas de laboratório: uma articulação possível. In: ENCONTRO NACIONAL DE PESQUISA EM EDUCAÇÃO EM CIÊNCIAS, 5., 2005, Bauru. Atas ... Bauru, ABRAPEC, 2005. p. 1-12.

SANTOS, F. M. T.; GOI, M. E. J. Resolução de Problemas no Ensino de Química fundamentos epistemológicos para o emprego da metodologia na Educação Básica. In:

ENCONTRO NACIONAL DE ENSINO DE QUÍMICA e X ENCONTRO DE EDUCAÇÃO QUÍMICA DA BAHIA, 16., Salvador, 2012. Anais... Salvador, UFBA, 2012. p. 1-11.

SILVA, E. R. A. Articulação entre Resolução de Problemas e a temática drogas como proposta metodológica para o Ensino de Química. 2017. Trabalho de Conclusão de Curso (Graduação) - Universidade Federal do Pampa, Caçapava do Sul/RS, 2017.

STAKE, R. E. Investigación com estudio de casos. Madrid: Morata, 2005.

WATTS, M. The science of problem solving: a pratical guide for science teachers. London: Cassell, 1991. 